\title{
High expression of HIF-2 $\alpha$ and its anti-radiotherapy effect in lung cancer stem cells
}

\author{
J.C. Sun, F. He, W. Yi, M.H. Wan, R. Li, X. Wei, R. Wu and D.L. Niu \\ Department of Radiation Oncology, The First Affiliated Hospital of Guangzhou \\ Medical University, Guangzhou, China \\ Corresponding authors: J.C. Sun / D.L. Niu \\ E-mail: sunjianc_cn@163.com / ndl_gmu@126.com \\ Genet. Mol. Res. 14 (4): 18110-18120 (2015) \\ Received August 23, 2015 \\ Accepted October 7, 2015 \\ Published December 22, 2015 \\ DOI http://dx.doi.org/10.4238/2015.December.22.37
}

ABSTRACT. Hypoxia-inducible factor-2 alpha (HIF-2a) has been shown to regulate cell stemness, although the expression and effects of HIF$2 \alpha$ in lung cancer stem cells remained unclear. This study investigated HIF-2 $\alpha$ expression in lung cancer stem cells, as well as the relationship between HIF-2 $\alpha$ expression and radioresistance in lung cancer cells. Stem-like cells $\left(\mathrm{CD} 133^{+}\right)$in the non-small-cell lung cancer cell line A549 were enriched by serum-free culture conditions, and CD133+ cells were sorted via fluorescence-activated cell sorting. A549 cells were treated with middle-infrared radiation, and the level of HIF-2 $\alpha$ expression was determined by a quantitative polymerase chain reaction assay and western blot analysis. The level of HIF-2 $\alpha$ expression in tissue sections from 50 cases of clinically confirmed non-small-cell lung cancer was determined via immunohistochemical analysis, and its correlation with prognosis after radiotherapy was analyzed. HIF-2 $\alpha$ levels in $\mathrm{CD}_{133^{+}}$cells were significantly higher than those in CD133 cells $(P=0.032)$. However, after radiation treatment, these levels were significantly upregulated in both $\mathrm{CD} 133^{+}$and CD133 cells $(P=0.031$ and $P=0.023$, respectively). After irradiation, the proportions of apoptotic, dead, and autophagic CD133+ A549 cells were 
considerably lower than those of CD133-A549 cells $(P<0.05)$. Furthermore, the recovery of carcinoembryonic antigen to pre-radiation levels was more rapid in lung cancer patients with high levels of HIF-2 $\alpha$ expression, and these patients had shorter survival times $(P=0.018)$. HIF-2 $\alpha$ is highly expressed in lung cancer stem cells, which may lead to radioresistance. In conclusion, HIF-2 $\alpha$ is a potential prognostic marker for lung cancer.

Key words: Lung cancer stem cell; HIF-2a; Anti-therapy; CD133; Radiation

\section{INTRODUCTION}

Lung cancers are malignant tumors that cause great harm to human health and life, and are characterized by increased incidence and mortality each year (Torre et al., 2015). However, effective treatments for lung cancer are lacking. Radiotherapy is currently the main first-line treatment for lung cancer, but the 5-year survival rate remains low at less than 20\% (Salama and Schild, 2015). In recent years, research has shown that the development and progression of cancer likely depends on a small number of tumor cells with characteristics of stem cells, which are referred to as cancer stem cells (Visvader and Lindeman, 2008). Cancer stem cells exhibit characteristics such as selfrenewal as well as resistance to chemotherapeutics and radiation damage, and the presence of these cancer stem cells is the basis for both tumor recurrence and metastasis (Clarke et al., 2006), and therefore may be the key to tumor treatment (Gorelik et al., 2010). Although cellular markers for lung cancer stem cells have only recently begun to be characterized, a number of studies have demonstrated that non-small-cell lung cancer $\mathrm{CD} 133^{+}$cells possess stem cell-like features (Chen et al., 2008; Eramo et al., 2008; Bertolini et al., 2009; Akunuru et al., 2012).

Hypoxia-inducible factors (HIFs), heterodimeric proteins composed of alpha (e.g., HIF-1 $\alpha$ and HIF-2 $\alpha$ ) and beta subunits (e.g., HIF-1 $\beta$ and HIF-2 $\beta$ ), are transcription factors and hypoxia stress factors (Koukourakis et al., 2001). HIFs are highly expressed during stress, and in turn induce the expression of anti-stress molecules within cells (Kaelin and Ratcliffe, 2008; Greer et al., 2012). However, several studies have demonstrated that there is an important relationship between HIF-2 $\alpha$ and stem cell induction (Kaufman, 2010; Cummins, 2012; Xu et al., 2012; Philip et al., 2013). For example, HIF-2 $\alpha$ can induce cells to express the stem cell-specific factor Oct-4, which is important for maintaining stemness (Covello et al., 2006; Koh et al., 2011). Additionally, HIF-2 $\alpha$ has been found to be highly expressed in glioma stem cells (Li et al., 2009a) and neuroblastoma cells (Pietras et al., 2008), but the function of HIF-2 $\alpha$ in lung cancer has not yet been described.

There have been many reports describing an essential role for HIF-1 in lung cancer progression. For example, HIF-1 $\alpha$ inhibits apoptosis and promotes the proliferation of lung cancer cells (Volm and Koomagi, 2000; Fan et al., 2002), regulates the tolerance to palladium drugs (Song et al., 2006), promotes angiogenesis in lung cancer (Jackson et al., 2010), promotes the proliferation of cancer cells (Wang et al., 2013), and promotes the migration of lung cancer cells (Li et al., 2009b). HIF-1a expression is significantly upregulated after surgery or radiotherapy (Zhang et al., 2009); therefore, HIF-1 $\alpha$ may serve as a biomarker to evaluate prognosis (Luan et al., 2013; Wang et al., 2014b), or serve as a target for treatment (Jacoby et al., 2010; Zhang et al., 2012). However, the role of HIF-2 $\alpha$ in lung cancer has rarely been reported on. It has recently been shown that HIF-2 $\alpha$ expression has some value in the post-operative assessment of lung cancer and the prognostic assessment of breast cancer (Wang et al., 2014a). Furthermore, HIF-2 $\alpha$ expression has important implications regarding anti-radiotherapy effects in esophageal cancer (Koukourakis et al., 2001), which suggests that HIF-2a may also have an impact on the radioresistance of lung cancer cells. 
Based on the aforementioned findings, this study investigated for the first time HIF-2 $\alpha$ expression in lung cancer stem cells, as well as the relationship between HIF-2a expression and radioresistance in lung cancer cells.

\section{MATERIAL AND METHODS}

\section{Cell culture}

The human lung epithelial cell line A549 (ATCC, Manassas, VA, USA) was used in this study. The cells were cultured in Dulbecco's modified Eagle's medium (DMEM, Invitrogen, Grand Island, NY, USA) supplemented with 10\% fetal bovine serum (Biological Industries, Beit Haemek, Israel). The cells were confirmed to be free of mycoplasma with a PCR-based detection method, and cells were cultured at $37^{\circ} \mathrm{C}$ with $5 \% \mathrm{CO}_{2}$.

Cells were cultured in serum-free conditions as previously described (Eramo et al., 2008). Briefly, cells were cultured at a clonal density in serum-free medium containing $50 \mathrm{mg} / \mathrm{mL}$ insulin, $100 \mathrm{mg} / \mathrm{mL}$ apotransferrin, $10 \mathrm{mg} / \mathrm{mL}$ putrescine, $0.03 \mathrm{mM}$ sodium selenite, $2 \mathrm{mM}$ progesterone, $0.6 \%$ glucose, $5 \mathrm{mM}$ HEPES, $0.1 \%$ sodium bicarbonate, $0.4 \% \mathrm{BSA}$, glutamine, and antibiotics in DMEM-F12 medium (Invitrogen) supplemented with $20 \mathrm{mg} / \mathrm{mL}$ EGF and $10 \mathrm{mg} / \mathrm{mL}$ bFGF.

\section{Fluorescence-activated cell sorting (FACS)}

For flow cytometry, single-cell suspensions of 4549 cells were incubated with the appropriate dilution of an isotype control or specific antibody. The antibodies used were PE-conjugated antiCD133 or APC-conjugated anti-CD133 from Miltenyi Biotec (Bergisch Gladbach, Germany). After a 45-min incubation with primary antibodies, the cells were washed before analysis and sorting using a BD LSRII Flow Cytometer (BD Biosciences, San Jose, CA, USA). Sorted CD133+ and CD133- A549 cells were cultured in DMEM supplemented with $10 \%$ fetal bovine serum (Biological Industries).

For the annexin V/propidium iodide (PI) assays, cells were stained with $10 \mu \mathrm{L}$ annexin V-FITC and $10 \mu \mathrm{L} \mathrm{PI}(5 \mu \mathrm{g} / \mathrm{mL})$ and stirred slowly for even mixing. Cells were placed in a dark room at room temperature for approximately $30 \mathrm{~min}$ and then $300 \mu \mathrm{L}$ binding buffer were added (10 mM HEPES, pH 7.4, $140 \mathrm{mM} \mathrm{NaOH}, 2.5 \mathrm{mM} \mathrm{CaCl}_{2}$ ). The cells were analyzed via flow cytometry and early apoptotic (annexin V-positive, PI-negative), late apoptotic (annexin V-positive and PIpositive), and dead (annexin V-negative and PI-positive) cells were counted to determine apoptosis and cell death.

\section{qPCR and western blotting}

For total RNA and total protein extraction, $10^{6}$ A549 cells were used. Total RNA was extracted using the TRIzol Reagent (Invitrogen) and was reverse-transcribed to cDNA using a kit from TOYOBO (Osaka, Japan). Real-time PCR was performed with a SYBR Premix EX Taq kit (Takara Dalian, Dalian, China) on an ABI Prism 7500 real-time PCR system (Applied Biosystems, Life Technologies, Carlsbad, CA, USA), with human GAPDH as the internal control. The following primers were used for qPCR analyses: HIF-2 $\alpha$ (5'-AGTTCTGGCTCCTGCAAGAA-3', 5'-AGTTCTGGC TCCTGCAAGAA-3' (Duan et al., 2014); GAPDH (5'-CGGAGTCAACGGATTTGGTCGTAT-3', 5'-TGCTAAGCAGTTGGTGGTGCAGGA-3'). 
Total protein was extracted using ice-cold RIPA buffer supplemented with phenylmethylsulfonyl fluoride (PMSF). Protein concentrations were determined using the bicinchoninic acid (BCA) assay according to manufacturer instructions. Proteins $(20 \mathrm{mg})$ from whole-cell lysates were separated via $10 \%$ SDS-PAGE and transferred to PVDF membranes (PALL Corporation, Port Washington, NY, USA). The membranes were blocked at room temperature with $5 \%$ nonfat dry milk in Tris-buffered saline (TBS) containing 0.1\% Tween-20 (TBST) and then incubated with an anti-HIF-2 $\alpha$ primary antibody (Beijing Biosynthesis Biotechnology Co., Beijing, China) $(1: 1000)$ and an anti-GAPDH antibody (each diluted 1:3000). The membranes were washed in TBST and incubated with a secondary horseradish peroxidase (HRP)-conjugated antibody (diluted 1:2000) for $1 \mathrm{~h}$ at room temperature. Bound antibody complexes were detected and visualized with SuperSignal West Pico enhanced chemiluminescence substrate (Thermo Scientific, Rockford, IL, USA).

\section{Sample collection}

Specimens from 50 non-small-cell lung cancer patients pathologically confirmed after surgery were collected and paraffin embedded at the General Hospital and Tianjin Chest Hospital from 2010 to 2014. The patients included 29 men and 21 women, ranging in age from 43 to 72 years (median age: 56.5 years). Pathological diagnoses were crosschecked by two senior pathologists. All of the specimens were taken before the patients were treated with radiotherapy. A follow-up by telephone was carried out to obtain information regarding the outcomes of the patients. The median follow-up time was 3 months. Overall survival was calculated from the time of surgery to the time of death, or to the date of the last follow-up.

This study was approved by the Ethics Committee of Tianjin Medical University, China, and the procedures were in accordance with the provisions of the Declaration of Helsinki. Written informed consent was obtained from all participants.

\section{Immunohistochemistry}

Paraffin-embedded sections $(5 \mu \mathrm{m})$ were deparaffinized and hydrated utilizing standard procedures. Immunostaining was performed using the Super-Sensitivity S-P IHC kit (Thermo, USA). An anti-HIF-2 $\alpha$ antibody (Beijing Biosynthesis Biotechnology Co.) was applied to the sections at a 1:400 dilution. Antigen retrieval was performed by a high-pressure method for $3 \mathrm{~min}$ in $0.1 \mathrm{M}$ citrate buffer ( $\mathrm{pH}$ 6.0). The staining was detected using a Real-Envision Detection kit (Gene Tech Company Limited, Shanghai, China).Three sections from each patient were immunohistochemically stained, and 5 fields of view from each section were randomly selected for microscopic imaging at 200X. The number of positive cells per field of view from all images was automatically counted with the Image $J$ software, and the average number of positive cells from all 15 images per patient was calculated. The 50 patients were divided into 5 groups according to the number of HIF-2 $\alpha^{+}$cells. To reach a balanced sample size in the 5 groups, the following classification criteria were applied: group A: less

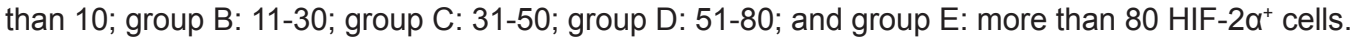

\section{Radiation}

Middle-infrared radiation (MIR) emission was performed as described previously (Chang et al., 2013). Briefly, cells were seeded on 12-well tissue culture plates (Corning Costar, Corning, NY, 
USA) $24 \mathrm{~h}$ before MIR exposure. The wavelength of MIR generated from the wide-band black body source was limited to a range of 3 to $5 \mu \mathrm{m}$. The wide-band pass filter was designed to isolate 3-5$\mathrm{mm}$ atmospheric windows with a diameter of $25.4 \mathrm{~mm}$. The $50 \%$ cut on/cut off transmission points were set at $3.0 \mu \mathrm{m} \pm 4 \%$ and $5.0 \mu \mathrm{m} \pm 4 \%$, respectively. The radiation intensity was measured by a THORLAB PM100D power meter (Newton, NJ, USA) to be $3 \mathrm{~mW} / \mathrm{cm}^{2}$.

\section{Statistical analysis}

T-tests, log-rank tests and survival curves were calculated using the SPSS20.0 software. The intensity of the western blot bands was measured with the ImageJ software. The significance level was set at $P<0.05$.

\section{RESULTS}

\section{Serum-free culture conditions can be used to enrich $\mathrm{CD}_{133^{+}}$lung cancer cells}

To separate CD133- and CD133+ $A 549$ cells, the cells were first cultured in serum-free medium for two passages, and then CD133+ A549 cells were sorted via FACS (Figure 1A and B). In the serum-cultured $A 549$ cells, the proportion of $C D 133^{+}$cells was only $1.14 \%$, whereas this proportion was significantly increased to $4.05 \%$ with serum-free culture conditions $(P=0.01$; Figure $1 C)$.
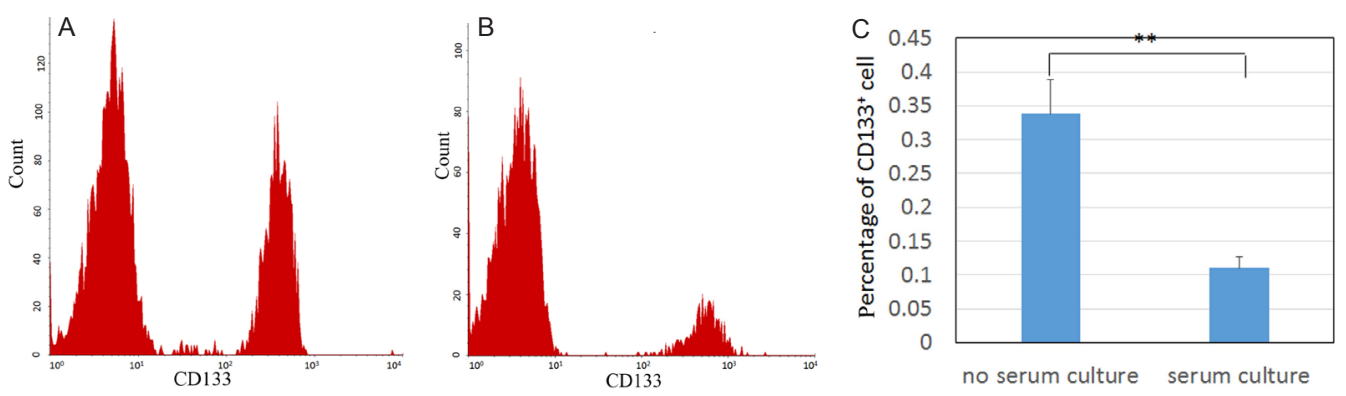

Figure 1. Serum-free culture conditions enrich CD133+ A549 cells. A. Serum-free-cultured A549 cells. B. Serumcultured A549 cells. C. Histogram demonstrating the percentage of $\mathrm{CD} 133^{+} \mathrm{A} 549$ cells among the total cell population.

\section{HIF-2 $\alpha$ expression was higher in CD133+ lung cancer cells than in CD133- cells}

To explore the relationship between HIF-2 $\alpha$ and lung cancer stem cells, the level of HIF-2 $\alpha$ expression in A549 CD133 $/$ cells was determined via qPCR (Figure 2A) and western blot analysis (Figure 2B and C). GAPDH was used as the internal control for both qPCR and western blotting. The data were normalized to GAPDH, and the results are displayed as the ratio of HIF-2 $\alpha$ to GAPDH. Results from the qPCR assay show that the level of HIF-2 $\alpha$ mRNA in the $\mathrm{CD}_{133^{+}}$cells was 3.5 times higher than that in the CD133- cells. Similarly, the western blot results revealed that the level of HIF-2a protein in the CD133+ cells was 3.6 times higher than that in the CD133- cells. 

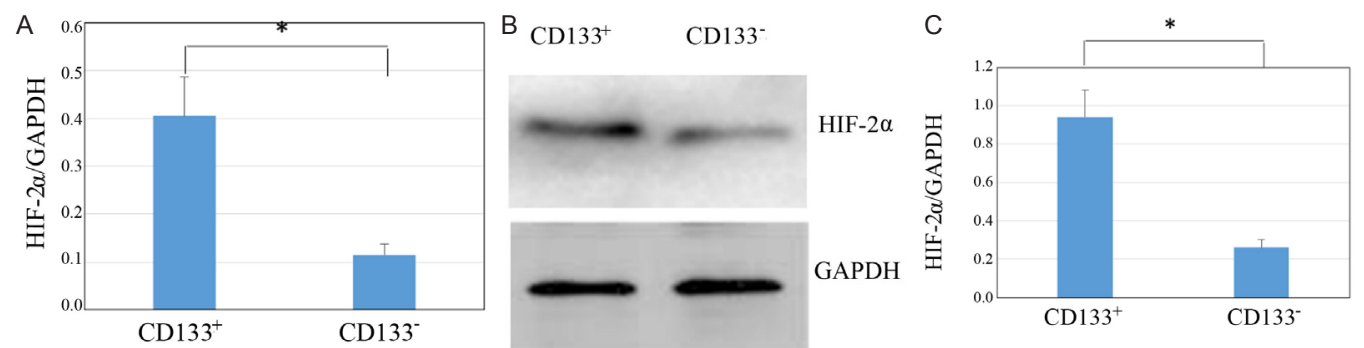

Figure 2. HIF-2 $\alpha$ is highly expressed in $\mathrm{CD}_{133^{+}} \mathrm{A} 549$ cells. A. qPCR detection of HIF-2 $\alpha$ mRNA levels in CD133+ $\mathrm{A} 549$ cells and CD133- A549 cells, with higher mRNA levels in CD133+ $A 549$ cells compared to those in CD133- A549 cells (GAPDH was used as the internal control; $N=5$; $t$-test; ${ }^{*} \mathrm{P}=0.043$ ). B. Western blot analysis of HIF-2 $\alpha$ protein levels in CD133+A549 cells and CD133-A549 cells. C. Quantitative analysis of bands according to the ImageJ software, indicating higher HIF-2 $\alpha$ protein levels in $\mathrm{CD} 133^{+}$A549 cells compared to those in CD133- A549 cells (GAPDH was used as internal control; $\mathrm{N}=5$; $t$-test; ${ }^{*} \mathrm{P}=0.032$ ).

\section{Expression of HIF-2 $\alpha$ in lung cancer cells was significantly increased after radiation treatment}

To investigate changes in HIF-2 $\alpha$ expression in lung cancer cells after radiation treatment, western blot analysis was utilized to detect HIF-2 $\alpha$ expression in A549 cells after irradiation (Figure 3A). HIF-2 $\alpha$ expression in the CD133+ A549 cells was increased by 1.8 -fold after radiation treatment, and we also observed a significant 2.6-fold expression increase in the CD133- A549 cells after radiation treatment (Figure 3B).
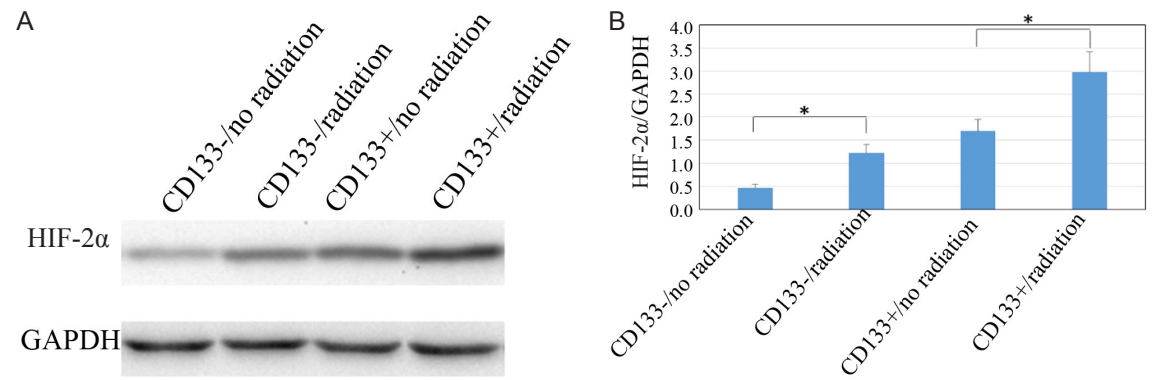

Figure 3. HIF-2 $\alpha$ is highly expressed in A549 cells after radiation treatment. A. Western blot analysis of the level of HIF-2 $\alpha$ expression in A549 cells. B. Quantitative analysis of the bands according to the ImageJ software, indicating increased HIF-2 $\alpha$ expression after radiation treatment both in CD133+ A549 cells and in CD133- A549 cells (GAPDH was used as internal control; $N=5 /$ group; $t$-test; ${ }^{*} \mathrm{P}=0.031$ and 0.023 , respectively).

\section{Radioresistance of CD133+ lung cancer cells was greater than that of CD133- cells}

To investigate the radioresistance of $\mathrm{CD} 133^{+}$and CD133- cells, flow cytometry was used to analyze apoptotic and dead A549 cells after radiation treatment (Figure 4A-E), and western blotting was used to analyze the level of autophagy in these cells (Figure 4F). The results show that the apoptotic rate of irradiated CD133- A549 cells increased by 4.6-fold, while necrotic cells increased by 4 -fold, and the autophagy marker LC3B was increased by 1.7-fold. However, for irradiated CD133+ A549 cells, the apoptotic rate only increased by 2.4 -fold, necrotic cells increased by 2.6 fold, and the autophagy marker LC3B was increased by 1.3 -fold, indicating that after radiation 
treatment, the levels of apoptosis, death, and autophagy were significantly lower in the CD133+ cells than those in the CD133- cells (Figure 4G).
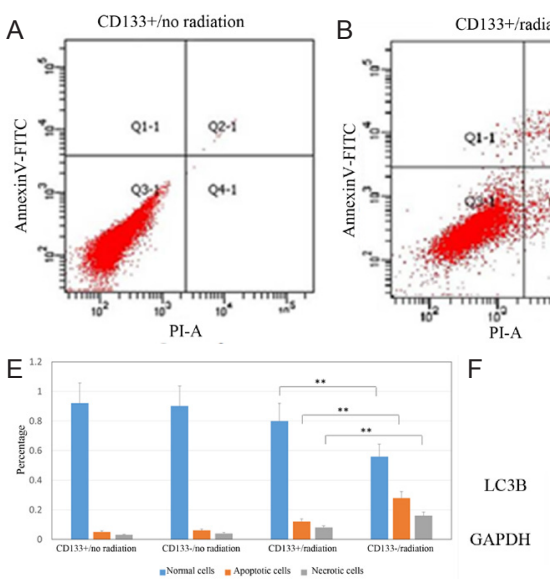

B CD133+/radiation

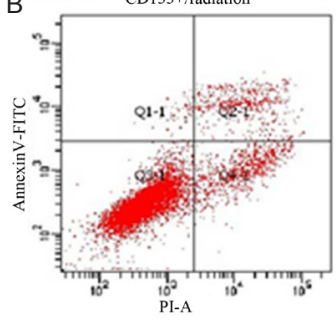

C
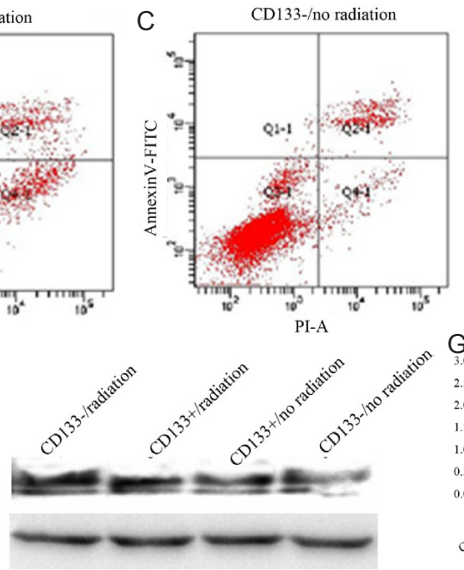
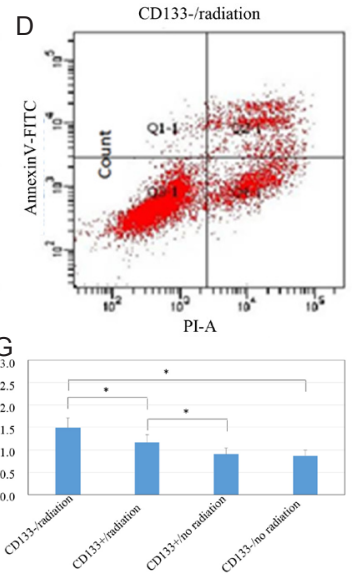

Figure 4. CD133+ A549 cells are more tolerant to radiation treatment than CD133- A549 cells. A.-D. Flow cytometry analysis of apoptosis and necrosis in A549 cells before and after radiation treatment. E. Flow cytometry results show that after radiation treatment, the levels of apoptosis and death are significantly increased in both the CD133 ${ }^{+}$A549 cells and the CD133- A549 cells, and that the proportions of apoptotic and dead CD133- cells are significantly higher than those in the $\mathrm{CD}_{133^{+}}$cells $\left(\mathrm{N}=5\right.$ /group; $t$-test; ${ }^{*} \mathrm{P}=0.044$ and 0.047$)$. $\mathrm{F}$. Western blot analysis of the autophagy marker LC3B within A549 cells. G. Quantitative analysis of the bands using the ImageJ software shows that there are increased LC3B protein levels after radiation treatment in both CD133+ A549 cells and CD133- A549 cells, with a greater fold-increase of LC3B in the CD133- cells compared to that in the CD133 ${ }^{+}$cells $\left(\mathrm{N}=5 / \mathrm{group} ; t\right.$-test; ${ }^{*} \mathrm{P}=0.033$ and $0.023,0.043$, respectively).

\section{High HIF-2 $\alpha$ expression levels were negatively correlated with prognosis in lung cancer patients}

To directly investigate the effect of HIF-2 $\alpha$ expression on the prognosis of patients with lung cancer after radiation treatment, samples from 50 cases of confirmed non-small-cell lung cancer were collected. The level of HIF-2 $\alpha$ expression prior to radiotherapy was measured via immunohistochemistry (Figure 5). Based on the number of HIF-2 $\alpha^{+}$cells, the 50 patients were divided into five groups (groups A-E): group A: less than 10 HIF-2 $\alpha^{+}$cells per field; group B: 10 to 30 HIF- $2 \alpha^{+}$cells per field; group C: 31 to 50 HIF- $2 \alpha^{+}$cells per field; group D: 51 to 80 HIF-2 $\alpha^{+}$cells per field; and group E: over 80 HIF-2 $\alpha^{+}$cells per field. The number of samples in the five groups was $11,13,8,9$, and 9 , respectively. The level of serum carcinoembryonic antigen (CEA) was assayed every month after radiotherapy and used to assess patient prognosis (Molina et al., 2003; Cedrés et al., 2011). The data are reported as means of the decreasing rates of all the samples from each group \pm the standard error. The results indicated that the CEA levels in most of the patients were significantly decreased in the first month after radiation therapy, but then began to gradually recover (Figure 5A and B). In addition, we found that in the 3rd, 4th, and 5th month after radiotherapy, the levels of CEA in groups $D$ and $E$ were significantly higher than that of group $A$ (Figure $5 C$ ). The survival analysis revealed that the survival curves became increasingly steep from group $A$ to group E, suggesting increasingly worse prognoses with increased HIF-2 $\alpha$ expression, and the expected average survival times were 15.1, 12.8, 11.1, 10.6, and 8.9 months, respectively (Figure 
5D and Table 1). A log-rank (Mantel-Cox) analysis indicated that there were significant differences in the survival curves among the different groups $(P=0.001)$, which suggests that the level of HIF$2 \alpha$ has a significant influence on the prognosis of lung cancer patients.
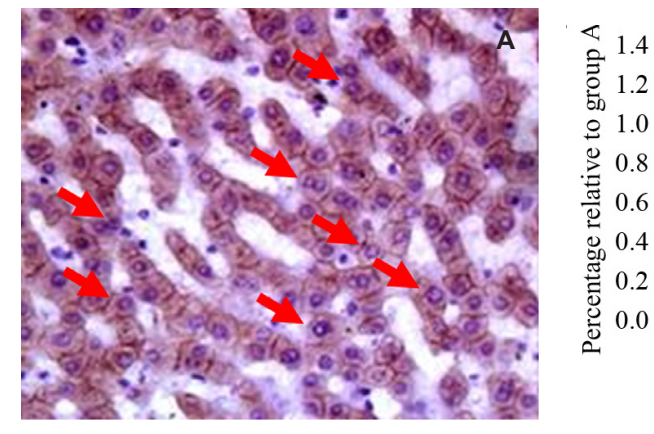

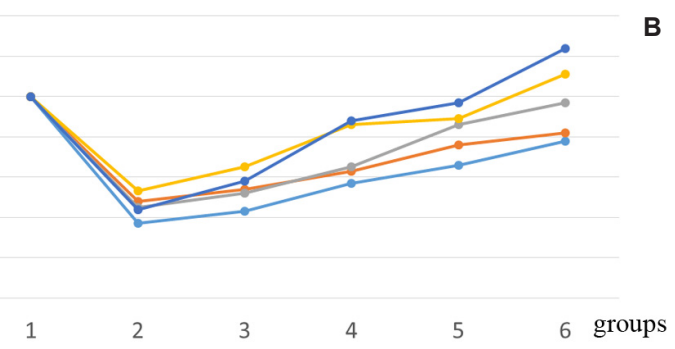

$\rightarrow$ Group A $\rightarrow$ Group B $\rightarrow$ Group C $\rightarrow$ Group D $\rightarrow$ Group E
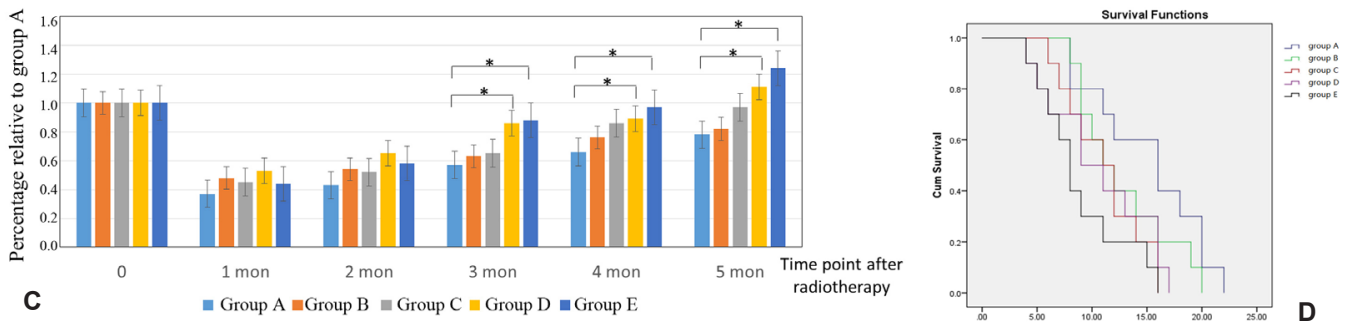

Figure 5. Level of HIF-2 $\alpha$ expression is negatively correlated with the prognosis of lung cancer patients treated with radiation. A. Immunohistochemical staining for HIF-2a in paraffin-embedded sections of samples from lung cancer patients revealing that HIF-2 $\alpha$ was mainly expressed in the nuclei of lung cancer cells. B. Based to the level of HIF-2 $\alpha$ expression, the patients were divided into five groups (groups A-E, with the level of HIF-2a gradually increasing from group $A$ to $E$ ), and their serum CEA levels were measured at different time points after radiotherapy (0: diagnosed with lung cancer but did not undergo any treatment; 1 mon: one month after radiotherapy; 2 mon: two months after radiotherapy; 3 mon: three months after radiotherapy; 4 mon: four months after radiotherapy; 5 mon: five months after radiotherapy; 6 mon: six months after radiotherapy; data are shown as the percentage of the CEA concentration at each time point relative to that at time point 0 ). C. CEA levels in patients are significantly decreased after radiotherapy in the first month, and then gradually increase, with a greater increase in group $D$ and group $E$ than that in group $A$. D. A survival curve analysis revealed that patients with high HIF-2 $\alpha$ expression levels had significantly shorter survival times.

Table 1. Means and medians for survival time.

\begin{tabular}{|c|c|c|c|c|c|c|}
\hline \multirow[t]{3}{*}{ Group } & \multicolumn{4}{|c|}{ Mean } & \multicolumn{2}{|c|}{ Median } \\
\hline & \multirow[t]{2}{*}{ Months } & \multirow[t]{2}{*}{ Std. error } & \multicolumn{2}{|c|}{$95 \%$ confidence interval } & \multirow[t]{2}{*}{ Months } & \multirow[t]{2}{*}{ Std. error } \\
\hline & & & Lower bound & Upper bound & & \\
\hline A & 30.2 & 3.22 & 23.9 & 36.5 & 32.0 & 6.20 \\
\hline B & 25.6 & 2.71 & 20.3 & 30.9 & 22.0 & 3.16 \\
\hline C & 22.2 & 2.26 & 17.8 & 26.6 & 22.0 & 3.16 \\
\hline D & 21.2 & 3.03 & 15.3 & 27.1 & 18.0 & 5.27 \\
\hline $\mathrm{E}$ & 17.8 & 2.54 & 12.8 & 22.8 & 16.0 & 1.55 \\
\hline Overall & 23.4 & 1.33 & 20.8 & 26.0 & 22.0 & 1.57 \\
\hline
\end{tabular}




\section{DISCUSSION}

Cancer stem cells are resistant to radiation damage, leading to difficulties in the treatment of lung cancer (Visvader and Lindeman, 2008). HIF-2 $\alpha$ is a hypoxia stress factor involved in the maintenance of cell stemness. Therefore, the present study investigated HIF-2 $\alpha$ expression in lung cancer stem cells and the correlation between HIF-2 $\alpha$ expression and the prognosis of lung cancer patients after radiotherapy. We found that HIF-2 $\alpha$ expression was significantly higher in A594 lung cancer stem cells (CD133+ A594) than that in normal lung cancer cells (CD133- A549), and after radiation treatment, HIF-2 $\alpha$ expression was significantly upregulated. Furthermore, high HIF-2 $\alpha$ expression was negatively correlated with the survival time of patients who underwent radiotherapy. These results indicate that HIF-2a may be a regulator of lung cancer stem cells and may be involved in radiotherapy resistance in lung cancer.

There have been numerous studies on the role of HIF-2 $\alpha$ in stem cells (Kaufman, 2010; Cummins, 2012; Xu et al., 2012; Philip et al., 2013). HIF-2a regulates the expression of the stem cell marker Oct-4 (Covello et al., 2006), and Oct-4 plays an important role in the maintenance of cell stemness. HIF-2 $\alpha$ expression has also been reported in cancer stem cells (Pietras et al., 2008; Li et al., 2009a). However, a role for HIF-2a in lung cancer stem cells has not been reported. Our study is the first to reveal that HIF-2 $\alpha$ expression is significantly higher in CD133+ A549 cells than in CD133- 4549 cells, consistent with previous findings that HIF-2 $\alpha$ is highly expressed in cancer stem cells including those in gliomas (Li et al., 2009a) and neuroblastomas (Pietras et al., 2008), which may indicate that HIF-2 $\alpha$ is widely expressed in cancer stem cells and is involved in regulating stemness. We also found that HIF-2 $\alpha$ expression was significantly increased in A549 cells after radiation treatment. This result is in accordance with pervious findings that demonstrated that there was an upregulation of HIF-2 $\alpha$ in esophageal cancer patients after radiotherapy (Koukourakis et al., 2001). Therefore, it is likely that HIF-2 $\alpha$ plays an important role in the response to external stimuli in addition to being involved in the regulation of cell stemness. However, further studies are required to understand the complete role of HIF-2 $\alpha$ in cancer stem cells.

We found that the prognosis of lung cancer patients with higher HIF-2a expression was poorer than those with lower HIF-2 $\alpha$ levels. This result is in agreement with findings from previous studies that showed that lung cancer patients with high HIF-2a levels had a poor prognosis after treatment, and that HIF-2 $\alpha$ was a predictive factor for prognosis (Wu et al., 2011; Wang et al., $2014 b$ ). Although our study focused on the relationship between pre-radiation HIF-2a levels and prognosis while previous studies focused on the relationship between post-radiation HIF-2 $\alpha$ levels and prognosis, the results from both methods revealed a negative correlation between HIF- $2 \alpha$ levels and prognosis in lung cancer. Moreover, others have found that HIF-2 $\alpha$ was highly expressed in breast cancer patients and could be used to assess prognosis in breast cancer (Wang et al., 2014a). Therefore, HIF-2a expression may serve as a prognostic factor in various cancers.

However, due to the small number of clinical samples herein, the application of HIF-2a in the prognostic assessment of lung cancer requires further study with greater sample numbers. Additionally, due to a lack of information regarding the exact staging of the clinical lung cancer samples collected in this study, and lack of data on whether or not the patients took other therapeutic drugs during this period, further investigations are required to confirm the negative correlation between HIF-2a levels and survival.

The present study supports a role for HIF-2a in lung cancer and in the prognostic evaluation of this disease, and our results suggest that HIF-2 $\alpha$ may be involved in the stemness 
and radioresistance of cancer stem cells. As HIF-2 $\alpha$ may be a potential therapeutic target for cancer treatment, this will be an important area for future research.

\title{
Conflicts of interest
}

The authors declare no conflict of interest.

\section{ACKNOWLEDGMENTS}

\author{
Research supported by the National Science Foundation for Young Scholars of China \\ (Grant \#81101701).
}

\section{REFERENCES}

Akunuru S, James Zhai Q and Zheng Y (2012). Non-small cell lung cancer stem/progenitor cells are enriched in multiple distinct phenotypic subpopulations and exhibit plasticity. Cell Death Dis. 3: e352.

Bertolini G, Roz L, Perego P, Tortoreto M, et al. (2009). Highly tumorigenic lung cancer CD133+ cells display stem-like features and are spared by cisplatin treatment. Proc. Natl. Acad. Sci. U. S. A. 106: 16281-16286.

Cedrés S, Nuñez I, Longo M, Martinez P, et al. (2011). Serum tumor markers CEA, CYFRA21-1, and CA-125 are associated with worse prognosis in advanced non-small-cell lung cancer (NSCLC). Clin. Lung Cancer 12: 172-179.

Chang HY, Shih MH, Huang HC, Tsai SR, et al. (2013). Middle infrared radiation induces G2/M cell cycle arrest in A549 lung cancer cells. PLoS One 8: e54117.

Chen YC, Hsu HS, Chen YW, Tsai TH, et al. (2008). Oct-4 expression maintained cancer stem-like properties in lung cancerderived CD133-positive cells. PLoS One 3: e2637.

Clarke MF, Dick JE, Dirks PB, Eaves CJ, et al. (2006). Cancer stem cells-perspectives on current status and future directions: AACR Workshop on cancer stem cells. Cancer Res. 66: 9339-9344.

Covello KL, Kehler J, Yu H, Gordan JD, et al. (2006). HIF-2alpha regulates Oct-4: effects of hypoxia on stem cell function, embryonic development, and tumor growth. Genes Dev. 20: 557-570.

Cummins EP (2012). HIF-2alpha - a mediator of stem cell altruism? Stem Cell Res. Ther. 3: 52.

Duan LJ, Takeda K and Fong GH (2014). Hypoxia inducible factor-2alpha regulates the development of retinal astrocytic network by maintaining adequate supply of astrocyte progenitors. PLoS One9: e84736.

Eramo A, Lotti F, Sette G, Pilozzi E, et al. (2008). Identification and expansion of the tumorigenic lung cancer stem cell population. Cell Death Differ. 15: 504-514.

Fan LF, Diao LM, Chen DJ, Liu MQ, et al. (2002). Expression of HIF-1 alpha and its relationship to apoptosis and proliferation in lung cancer. Ai Zheng 21: 254-258.

Gorelik E, Lokshin A and Levina V (2010). Lung cancer stem cells as a target for therapy. Anticancer Agents Med. Chem. 10: 164-171.

Greer SN, Metcalf JL, Wang Y and Ohh M (2012). The updated biology of hypoxia-inducible factor. EMBO J. 31: 2448-2460.

Jackson AL, Zhou B and Kim WY (2010). HIF, hypoxia and the role of angiogenesis in non-small cell lung cancer. Expert Opin. Ther. Targets 14: 1047-1057.

Jacoby JJ, Erez B, Korshunova MV, Williams RR, et al. (2010). Treatment with HIF-1alpha antagonist PX-478 inhibits progression and spread of orthotopic human small cell lung cancer and lung adenocarcinoma in mice. J. Thorac. Oncol. 5: $940-949$

Janikova M, Skarda J, Dziechciarkova M, Radova L, et al. (2010). Identification of CD133+/nestin+ putative cancer stem cells in non-small cell lung cancer. Biomed. Pap. Med. Fac. Univ. Palacky. Olomouc. Czech. Repub. 154: 321-326.

Kaelin WG Jr and Ratcliffe PJ (2008). Oxygen sensing by metazoans: the central role of the HIF hydroxylase pathway. Mol. Cell 30: 393-402.

Kaufman DS (2010). HIF hits Wnt in the stem cell niche. Nat. Cell Biol. 12: 926-927.

Koh MY, Lemos R Jr, Liu X and Powis G (2011). The hypoxia-associated factor switches cells from HIF-1alpha- to HIF-2alphadependent signaling promoting stem cell characteristics, aggressive tumor growth and invasion. Cancer Res. 71: 4015-4027.

Koukourakis MI, Giatromanolaki A, Skarlatos J, Corti L, et al. (2001). Hypoxia inducible factor (HIF-1a and HIF-2a) expression in early esophageal cancer and response to photodynamic therapy and radiotherapy. Cancer Res. 61: 1830-1832.

Li Y, Qiu X, Zhang S, Zhang Q, et al. (2009a). Hypoxia induced CCR7 expression via HIF-1alpha and HIF-2alpha correlates 
with migration and invasion in lung cancer cells. Cancer Biol. Ther. 8: 322-330.

Li Z, Bao S, Wu Q, Wang H, et al. (2009b). Hypoxia-inducible factors regulate tumorigenic capacity of glioma stem cells. Cancer Cell 15: 501-513.

Luan Y, Gao C, Miao Y, Li Y, et al. (2013). Clinicopathological and prognostic significance of HIF-1alpha and HIF-2alpha expression in small cell lung cancer. Pathol. Res. Pract. 209: 184-189.

Molina R, Filella X, Augé JM, Fuentes R, et al. (2003). Tumor markers (CEA, CA 125, CYFRA 21-1, SCC and NSE) in patients with non-small cell lung cancer as an aid in histological diagnosis and prognosis. Comparison with the main clinical and pathological prognostic factors. Tumour Biol. 24: 209-218.

Philip B, Ito K, Moreno-Sánchez R and Ralph SJ (2013). HIF expression and the role of hypoxic microenvironments within primary tumours as protective sites driving cancer stem cell renewal and metastatic progression. Carcinogenesis 34 : 1699-1707.

Pietras A, Gisselsson D, Ora I, Noguera R, et al. (2008). High levels of HIF-2alpha highlight an immature neural crest-like neuroblastoma cell cohort located in a perivascular niche. J. Pathol. 214: 482-488.

Qu H, Li R, Liu Z, Zhang J, et al. (2013). Prognostic value of cancer stem cell marker CD133 expression in non-small cell lung cancer: a systematic review. Int. J. Clin. Exp. Pathol. 6: 2644-2650.

Salama JK and Schild SE (2015). Radiation therapy for oligometastatic non-small cell lung cancer. Cancer Metastasis Rev. 34: 183-193.

Salnikov AV, Gladkich J, Moldenhauer G, Volm M, et al. (2010). CD133 is indicative for a resistance phenotype but does not represent a prognostic marker for survival of non-small cell lung cancer patients. Int. J. Cancer 126: 950-958.

Sarvi S, Mackinnon AC, Avlonitis N, Bradley M, et al. (2014). CD133+ cancer stem-like cells in small cell lung cancer are highly tumorigenic and chemoresistant but sensitive to a novel neuropeptide antagonist. Cancer Res. 74: 1554-1565.

Song X, Liu X, Chi W, Liu Y, et al. (2006). Hypoxia-induced resistance to cisplatin and doxorubicin in non-small cell lung cancer is inhibited by silencing of HIF-1alpha gene. Cancer Chemother. Pharmacol. 58: 776-784.

Torre LA, Bray F, Siegel RL, Ferlay J, et al. (2015). Global cancer statistics, 2012. CA Cancer J. Clin. 65: 87-108.

Visvader JE and Lindeman GJ (2008). Cancer stem cells in solid tumours: accumulating evidence and unresolved questions. Nat. Rev. Cancer 8: 755-768.

Volm M and Koomagi R (2000). Hypoxia-inducible factor (HIF-1) and its relationship to apoptosis and proliferation in lung cancer. Anticancer Res. 20: 1527-1533.

Wang HX, Qin C, Han FY, Wang XH, et al. (2014a). HIF-2alpha as a prognostic marker for breast cancer progression and patient survival. Genet. Mol. Res. 13: 2817-2826.

Wang Q, Li LH, Gao GD, Wang G, et al. (2013). HIF-1alpha up-regulates NDRG1 expression through binding to NDRG1 promoter, leading to proliferation of lung cancer A549 cells. Mol. Biol. Rep. 40: 3723-3729.

Wang Q, Hu DF, Rui Y, Jiang AB, et al. (2014b). Prognosis value of HIF-1alpha expression in patients with non-small cell lung cancer. Gene 541: 69-74.

Wu XH, Qian C and Yuan K (2011). Correlations of hypoxia-inducible factor-1alpha/hypoxia-inducible factor-2alpha expression with angiogenesis factors expression and prognosis in non-small cell lung cancer. Chin. Med. J. (Engl.) 124: 11-18.

Xu Y, Li Y, Pang Y, Ling M, et al. (2012). EMT and stem cell-like properties associated with HIF-2alpha are involved in arseniteinduced transformation of human bronchial epithelial cells. PLoS One7: e37765.

Zhang L, Ge W, Hu K, Zhang Y, et al. (2012). Endostar down-regulates HIF-1 and VEGF expression and enhances the radioresponse to human lung adenocarcinoma cancer cells. Mol. Biol. Rep. 39: 89-95.

Zhang Y, Ge W, Zhao J, Zhao Z, et al. (2009). The Effect of Endostatin and Radiotherapy on Human Lung Cancer Cell Line A549 and the Impact of HIF-1 Expression after Therapy. Zhongguo Fei Ai Za Zhi 12: 33-37. 